\title{
Scientific and local ecological knowledge, shaping perceptions towards protected areas and related ecosystem services
}

\author{
M. A. Cebrián-Piqueras (ID) A. Filyushkina (1D) D. N. Johnson (I)

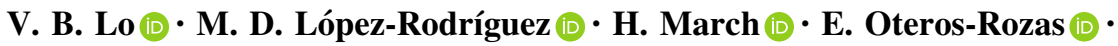 \\ C. Peppler-Lisbach $(1)$ C. Quintas-Soriano 1 - C. M. Raymond $(\mathbb{D} \cdot$

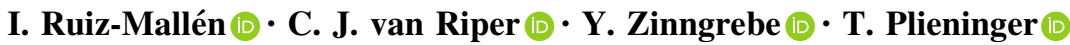

Received: 23 January 2020/ Accepted: 31 August 2020/Published online: 11 September 2020

(C) The Author(s) 2020

\begin{abstract}
Context Most protected areas are managed based on objectives related to scientific ecological knowledge of species and ecosystems. However, a core principle of sustainability science is that understanding and including local ecological knowledge, perceptions of ecosystem service provision and landscape vulnerability will improve sustainability and resilience of social-ecological systems. Here, we take up these assumptions in the context of protected areas to
\end{abstract}

Electronic supplementary material The online version of this article (https://doi.org/10.1007/s10980-020-01107-4) contains supplementary material, which is available to authorized users.

M. A. Cebrián-Piqueras $(\varangle) \cdot$ Y. Zinngrebe ·

T. Plieninger

Department of Agricultural Economics and Rural Development, University of Göttingen, Platz der Göttinger Sieben 5, 37073 Göttingen, Germany

e-mail: cebrian@uni-goettingen.de

A. Filyushkina

Institute for Environmental Studies (IVM), Vrije

Universiteit Amsterdam, De Boelelaan 1087,

1081 HV Amsterdam, The Netherlands

D. N. Johnson · C. J. van Riper

Department of Natural Resources and Environmental

Sciences, University of Illinois at Urbana-Champaign,

Urbana, IL, USA provide insight on the effectiveness of nature protection goals, particularly in highly human-influenced landscapes.

Objectives We examined how residents' ecological knowledge systems, comprised of both local and scientific, mediated the relationship between their characteristics and a set of variables that represented perceptions of ecosystem services, landscape change, human-nature relationships, and impacts.

Methods We administered a face-to-face survey to local residents in the Sierra de Guadarrama protected areas, Spain. We used bi- and multi-variate analysis, including partial least squares path modeling to test our hypotheses.

\section{B. Lo · C. M. Raymond}

Department of Landscape Architecture, Planning and Management, Swedish University of Agricultural Sciences, Sundsvägen 4, 23053 Alnarp, Sweden

M. D. López-Rodríguez · H. March · I. Ruiz-Mallén Internet Interdisciplinary Institute (IN3), Universitat Oberta de Catalunya, Av. Carl Friedrich Gauss, Parc Mediterrani de La Tecnologia, Castelldefels, 08860 Barcelona, Spain

H. March

Estudis d'Economia i Empresa, Universitat Oberta de Catalunya, Av. Tibidabo 39-43, Barcelona 08035, Spain

E. Oteros-Rozas

Chair On Agroecology and Food Systems, University of Vic-Central University of Catalonia (UVic-UCC), C. de la Laura, 13, 08500 Vic, Spain 
Results Ecological knowledge systems were highly correlated and were instrumental in predicting perceptions of water-related ecosystem services, landscape change, increasing outdoors activities, and human-nature relationships. Engagement with nature, socio-demographics, trip characteristics, and a ruralurban gradient explained a high degree of variation in ecological knowledge. Bundles of perceived ecosystem services and impacts, in relation to ecological knowledge, emerged as social representation on how residents relate to, understand, and perceive landscapes.

Conclusions Our findings provide insight into the interactions between ecological knowledge systems and their role in shaping perceptions of local communities about protected areas. These results are expected to inform protected area management and landscape sustainability.

Keywords Traditional ecological knowledge ·

Ecosystem services $\cdot$ Protected areas $\cdot$ Local community $\cdot$ Ecosystem vulnerability $\cdot$ Biodiversity . Landscape sustainability $\cdot$ Human-nature

relationships $\cdot$ Inclusive conservation

\section{Introduction}

Protected area (PA) networks are the most recognized and accepted strategy for conserving biodiversity in the face of global land use change (e.g. ecosystem fragmentation and agricultural intensification; Gray et al. 2016), yet capacity for long term protection of

C. Peppler-Lisbach

IBU, Landscape Ecology Group, University of Oldenburg, P.O. Box 2503, 26111 Oldenburg, Germany

C. Quintas-Soriano - T. Plieninger

Faculty of Organic Agricultural Sciences, University of

Kassel, Steinstr. 19, 37213 Witzenhausen, Germany

C. M. Raymond

Helsinki Institute of Sustainability Science, University of Helsinki, Helsinki, Finland

C. M. Raymond

Ecosystems and Environment Research Program, Faculty of Biological and Environmental Sciences, University of Helsinki, P.O. Box 65, 00014 Helsinki, Finland wide-ranging ecosystem services (ES) is increasingly uncertain (Xu et al. 2017). The Convention for Biological Diversity (CBD) and its 196 parties defines the strategic target to effectively conserve $17 \%$ of every member state's terrestrial surface area within PAs by 2020 (Aichi Target 11 of the Strategic Plan 2011-2020). However, less than $15 \%$ of terrestrial and $10 \%$ of marine areas are designated as protected globally and the rate of designation remains insufficient for achieving global biodiversity targets and growing demand for ES (Le Saout et al. 2013; Watson et al. 2014). Specifically, in Spain, PAs span $27 \%$ of terrestrial and $13 \%$ of marine area (EUROPARCEspaña 2019). Although protection and enhancement of ecosystems and biodiversity have been central goals of nature protection in PAs during past decades, it has increasingly been acknowledged that successful protection and management might be partly related to understanding the multiple ways in which humans value, relate to, and perceive benefits of and threats to ecosystems (e.g. perceptions of ES supply or nature contributions to people; Palomo et al. 2014; Bennett 2016; Díaz et al. 2018). For instance, the way local communities perceive their landscapes and the management practices can directly affect processes of legitimacy for conservation governance or social acceptance (Bennett 2016). Assessing human knowledge about natural processes and biocultural diversity is therefore instrumental for designing conservation strategies for PAs that are understood, legitimized, and accepted by local residents or stakeholders (Mace 2014; Tengö et al. 2017; Díaz et al. 2019).

Identifying, evaluating, and employing multiple mechanisms of knowing and learning are key tenets of

\section{M. Raymond}

Department of Economics and Management, Faculty of Agriculture and Forestry Sciences, University of Helsinki, P.O. Box 65, 00014 Helsinki, Finland

Y. Zinngrebe

Department Naturschutzforschung, Helmholtz-Zentrum für Umweltforschung - UFZ, Permoserstr. 15, 04318 Leipzig, Germany 
sustainability science (Miller 2013) and landscape sustainability science (Opdam et al. 2018). Representing multiple voices in PA management requires developing pathways for understanding different knowledge systems. On the one hand, scientific ecological knowledge (SEK) and research on biodiversity have traditionally supported and informed the establishment of PAs (Le Saout et al. 2013; Palomo et al. 2014; Watson et al. 2014). SEK is generated through a strict and universally accepted set of rules informed by academic disciplines (e.g. ecology, biology or forestry) and by the scientific method (Raymond et al. 2010). On the other hand, people living within and around PAs hold a cumulative body of non-scientific knowledge, beliefs and practices about local ecosystems and their management that is grounded in local experience. By relying on such traditional or local ecological knowledge (LEK) many rural communities have historically been able to conserve biodiversity while supporting their livelihoods and dealing with uncertainty (Berkes 1999). LEK broadly refers to knowledge that is held by a specific group of people about their local ecosystems, and has been derived from human-environment interactions (Raymond et al. 2010). Recent studies suggest that assessing PA residents' LEK is essential for exploring co-management options, adaptation alternatives, and integration of knowledge processes which can guide future landscape and nature management policies (Palomo 2017). Other studies revealed the importance of including ecological knowledge (EK) for the improvement of conservation goals, independently of its form (e.g. SEK or LEK) (Coreau et al. 2018). Understanding and considering sociocultural or biocultural values and the associated practices, often embedded in LEK, might improve the resilience of social-ecological systems in PAs and the efficacy of nature protection goals (GómezBaggethun et al. 2012).

Past research has emphasized the importance of evaluating LEK in the context of marine PAs (Gerhardinger et al. 2009), rangelands (Apio et al. 2015), or agro-ecosystems (Iniesta-Arandia et al. 2014), acknowledging that high levels of LEK can support nature conservation attitudes (Braga et al. 2017), improve socio-ecological resilience (Reid et al. 2006; Díaz et al. 2018), and reduce conflict (i.e. social, sectorial and political) between stakeholders and PA governing entities at multiples scales (Kati et al.
2015). Some studies have extended this body of work, highlighting the permeability or interaction between distinct knowledge systems, suggesting interdependence (Frazão-Moreira et al. 2009) or complementarity (Ruiz-Mallén et al. 2009) between LEK and SEK. For example, educational research tested the associations between these two bodies of knowledge with indigenous adolescents and found that they complemented each other, contributing to young people's environmental learning (Ruiz-Mallén et al. 2009). Incorporating distinct knowledge systems into resource management is inherently complex and context dependent, in part because scientific and local knowledge are informed by different research questions, methodological approaches, and terminologies (Moon and Blackman 2014; Lemos et al. 2018). To address this complexity, a shift from development of knowledge integration products to problem-focused integration processes is required (Raymond et al. 2010; Tengö et al. 2017).

While the need for integrating multiple knowledge systems and perceptions of landscapes into nature conservation has been recognized (Mace 2014; Tallis and Lubchenco 2014; Bennett 2016), empirical evidence explaining the variation and interaction between LEK and SEK and how they explain perceptions of ES remains scarce (Lamarque et al. 2011; Martín-López et al. 2012; Cebrián-Piqueras et al. 2017). Understanding PA residents' SEK and LEK and how they influence perceptions about landscapes in PAs could help to identify which knowledge systems or pockets of knowledge are relevant and vulnerable and need to be integrated in management and conservation strategies and plans (Reyes-García et al. 2014).

This study aimed to address this gap by delineating two different bodies of ecological knowledge i.e. SEK and LEK, about biodiversity and ecosystems among the residents living within and around the PAs of the mountain system of the Sierra de Guadarrama (SG), Spain. Our work was guided by the following four objectives:

(1) To examine perceptions of: (i) ecosystem service provision; (ii) landscape change, (iii) vulnerability and (iv) human-nature relationships;

(2) To assess a series of factors that describe the respondents and are expected to explain ecological knowledge and landscape perceptions 
including socio-demographics, trip characteristics, engagement with nature, and a rural-urban gradient, and;

(3) To determine how LEK and SEK are explained by the characteristics of respondents, and in turn, provide insight on perceptions.

(4) To provide insights about the implications of the results for landscape sustainability and management of PAs.

We hypothesized that both forms of ecological knowledge (i.e. LEK and SEK) are positively correlated with the value local residents attribute to ecosystem services (building on Raymond et al. 2009), while perceived bundles of ES may be explained by different knowledge systems or stakeholder groups (Cebrián-Piqueras et al. 2017). Bundles are common sets of ES that appear repeatedly together across space or time (Martín-López et al. 2012). Similarly, we expected that more knowledgeable residents would perceive more changes and vulnerability to the SG landscape given the importance of knowledge and cultural worldviews for shaping concerns about environmental impacts (Shi et al. 2015) and ecosystem resilience (Alessa et al. 2003). We also hypothesized that a broad spectrum of perceived human-nature relationships would be associated with greater ecological knowledge, particularly higher LEK. Finally, we expected that four groups of factors including socio-demographics, trip characteristics, previous engagement with nature, and a rural-urban gradient would shape differently ecological knowledge systems. We statistically tested these assumptions and then discussed how resident visions, understood here as perceived social representations of landscapes (Quétier et al. 2010) elicited from the results, link to international and regional strategies, policies, conservation models (Mace 2014) and the network of local PAs, and can offer insights for landscape sustainability and management within and around the landscapes of SG.

\section{Methods}

Study site

This research was conducted in the Sierra de Guadarrama (SG) mountain range located in the central mountain systems of the Iberian Peninsula. Spanning 180.000 ha approximately and located in the Madrid and Segovia provinces (Spain) (Fig. 1), the predominant climate of this area is continental Mediterranean with high seasonal temperature fluctuations and precipitation. The average temperatures on the coldest and warmest months are $0.7{ }^{\circ} \mathrm{C}$ and $16.4{ }^{\circ} \mathrm{C}$ respectively, and the rainfall is $1325 \mathrm{~mm}$ per year (AEMET 2019). Central to this area is SG National Park which includes features such as glacial cirques, lakes, and unique granite rock formations, as well as several Iberian endemic species. The biological relevance of the area has been recognized in protection regimes at global, continental, national, and regional scales with the establishment of several PAs and two UNESCO Man and Biosphere Reserves.

The SG is intersected by 34 municipalities that constitute the Area of Socio-economic Influence, defined as the municipalities contributing with land to the national park, and other close municipalities, such as Bustarviejo, which have strong geographic and cultural relations with the site. Traditionally, the predominant land-uses included livestock farming and pinewood timber logging. However, due to parallel effects of land intensification and rural abandonment, current economic drivers are related to animal husbandry and tourism based on the natural values of the landscape. Due to the proximity to the metropolitan area of Madrid (ca. 5.5 million inhabitants), SG has experienced rapid population growth in recent years. The area of socio-economic influence has grown to around 175,593 inhabitants (2018), which tends to increase on weekends and the summer season as a consequence of almost three million visitors per year that have been estimated for the national park (Albacete 2015).

\section{Data collection}

Data for this research were collected from a face-toface survey administered to residents of municipalities adjacent to the SG mountain range in SeptemberOctober 2019 (175,593 inhabitants). We focused on municipalities from the Area of Socio-economic Influence of the National Park and a municipality, Bustarviejo, geographically related to the system of SG. We collected a sample of the general population stratified by gender, age, and geographical distribution using an adapted snowball sampling method 


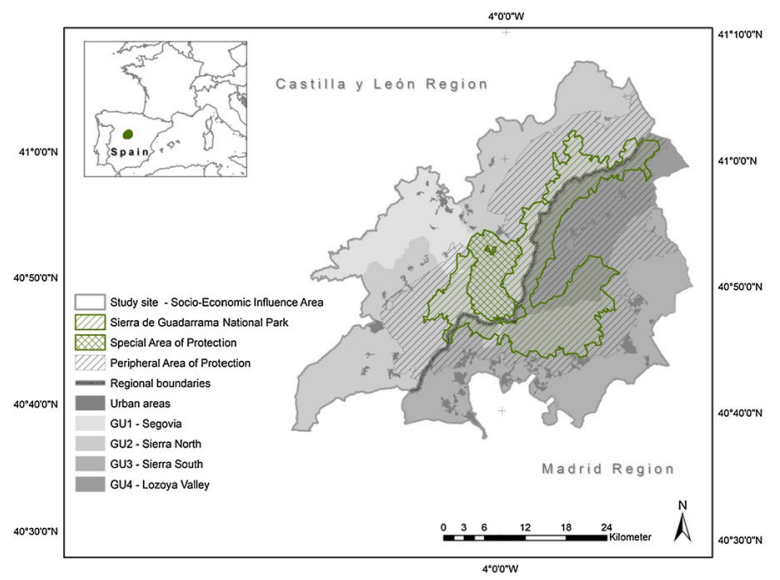

Fig. 1 Location of the study site. $G U$ geographic units

(Heckathorn 2011) and approached 186 local residents to participate in the study (See section "Characteristics of respondents" for sample details). We used portable computers that recorded data with the cloud software Maptionnaire (https://maptionnaire.com). A total number of 161 respondents completed the survey and were included in this study (response rate $=87 \%$ ). The questionnaire recorded: socio-demographic characteristics; ecological knowledge; and perceptions of ES, landscape vulnerability and change, human-nature relationships, and ecosystems value in relation to biodiversity and human well-being (Table 2 in Supplementary Material (SM)).

\section{Survey measures}

\section{Predictors of ecological knowledge}

Socio-demographics and trip characteristics Sociodemographic information related to monthly income, age, gender, education, municipality of residence, years living in the site, and occupation were included in the survey. To assess trip characteristics two indicators were obtained. First, an environmentrelated profession variable was created using a binary scale $(1=$ related; $0=$ unrelated). Second, the absolute number of visits to the study site was transformed into a 5-level ordinal scale called visits to site (Table 2 in $\mathrm{SM}$ ).

Engagement with nature Respondents identified mechanisms in which they were exposed to the study site's landscapes by selecting a range of activities

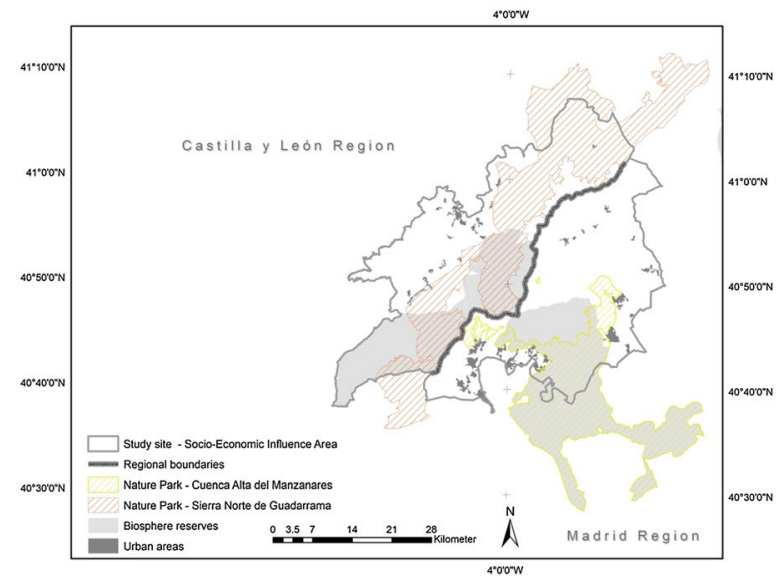

( $\mathrm{n}=11)$ such as mushrooms and plants picking, sports, nature observation, picnic and recreation, hunting, fishing, hiking and walking, walking dog, horse riding, bathing, or photography and other arts. Responses to these items were coded as single binary variables (i.e., $1=$ presence; $0=$ absence) to measure nature exposure. Learning exposure, was measured using a similar scale that included seven sources through which respondents had the opportunity to learn about landscapes of the study site, including primary, secondary or university school; direct contact with the natural environment; reading; television; seminars or courses related to the topic; internet; in contact with other people. Each form of learning about landscapes was treated individually and coded with a binary scale.

Urban-rural gradient To characterize the urbanrural gradient we used four basic indicators derived from resident municipalities including population, population density, distance to an urban center (i.e. minimum distance to area with at least 30,000 inhabitants), and altitude. Municipalities were assigned to four distinctive geographical units based on socio-cultural, geographic, and socio-economic criteria as well as expert interviews (Albacete 2015): Segovia municipality (Segovia province capital; GU1); Sierra-North (GU2); Sierra-South (GU3); and Lozoya Valley (GU4).

\section{Ecological knowledge}

We used adapted scales from previous work to measure SEK and LEK of SG's biodiversity and 
ecosystems (Reyes-García et al. 2014; Gómez-Baggethun et al. 2010). These two types of knowledge were evaluated using scores from a set of eight questions about ecological knowledge that were weighted means of ordinal scales. We measured SEK using responses to the first four items, which focused on scientific terminology for ecosystem or species names in relation to biodiversity and formal nature. The SEK questions did not reference local landscape use or traditional practices: Score SEK1: Do you know any of these terms related to species? (1) Endangered species, (2) alien invasive species, (3) native species, (4) endemic species and (5) migratory species. Score SEK 2: Could you mention one species belonging to each of the previous categories? i.e. endangered, alien invasive, indigenous and endemic species. Score SEK3: How many of these landscapes or ecosystems present in the Sierra de Guadarrama do you know? (A panel containing pictures representing the most representative ecosystems was shown: (1) Wood pastures ("Dehesas"); (2) oak forest of Quercus pyrenaica; (3) holm oak forest; (4) scots pine forest; (5) rivers and water courses; (6) riparian forest; (7) European holly forest (Ilex aquifolium), (8) valley pastures and meadows; (9) mountain lakes and peatlands (10) high altitude pastures and padded brushwood ("Piornal"); (11) fragmentary rocky rubbles ("Canchales") (Albacete 2015). Score SEK4: Can you mention any species commonly found in the previous ecosystems (e.g. species of flora, fauna, fungus ...)?. We measured LEK by using four questions related to human practices and uses associated with biodiversity and the SG landscape: Score LEK1: Could you provide some examples of wild plants useful for humans in the landscapes of the Sierra de Guadarrama? If so, what are they used for?; Score LEK2: Do you know any traditional practices or uses related to these landscapes and their nature? If so, which ones? Could you describe them briefly?. Score LEK 3: Do you currently use some species of plants or animals from the landscapes of the Sierra?, If so, which ones, what do you use them for? And how did you learn the related technique?). Score LEK 4: Could you mention any traditional practice associated with one or more of the previous landscapes?. Two final global scores were calculated for each knowledge type after score standardization and by using a weighted mean:

$$
\begin{aligned}
\text { Global score SEK }= & S E K 1 * 0.10+S E K 2 * 0.40 \\
& +S E K 3 * 0.10+S E K 4 * 0.40 .
\end{aligned}
$$

Global score $L E K=L E K 1 * 0.25+L E K 2 * 0.25$

$$
+L E K 3 * 0.25+L E K 4 * 0.25 \text {. }
$$

The selection of questions and score weights were informed by pilot test data collected in July 2019 with local residents $(n=15)$. Finally, due to high correlation between SEK and LEK, and similitude on how they related to respondent characteristics and perception, both knowledge scores were summed into an ecological knowledge (EK) variable $(\mathrm{EK}=\mathrm{SEK}+\mathrm{LEK})$.

Perceptions of landscapes

Perceptions of ES supply Respondents were asked about the perceived importance of the study site for the provision of various ES on a Likert scale ranging from 1 (irrelevant) to 10 (highly relevant) (CebriánPiqueras et al. 2017). The final range of ES was tailored to the context based on pilot data resulting in sixteen ES that were grouped into three major categories of ES (Table 2 in SM) (CICES classification) including. regulating $(\mathrm{n}=8)$ cultural $(n=4)$, and provisioning $(n=4)$. A composite score was calculated using the mean value of responses to all $16 \mathrm{ES}$ and called landscape value.

Perceptions about landscape vulnerability These perceptions were measured using a Likert scale ranging from 1 (irrelevant) to 10 (highly relevant) of eight major impacts and threats. The list of impacts and threats was drawn from pilot test data and included growing urbanization, abandonment of traditional uses, environmental change, alien species, overexploitation of resources, mass tourism, sport activities, pollution (Table 2 in SM). A composite score was calculated from the mean value of all items resulting in the variable, landscape vulnerability.

Perceptions about human-nature relationships Theses perceptions were evaluated using two questions about positive human-nature relationships and negative human-nature relationships between species and humans measured on a 3-point Likert scale ranging from "no perceived 
interaction" to "perceived interaction." (i.e. (1) Do you think that some wild species could benefit from human uses in the landscape? If so, what species? Why? (2) Do you think there are some native species that could be causing impacts to human activities and/ or ecosystems in general? If so, which ones? And why?). A third question evaluated the perceived effects of traditional practices on nature conservation objectives; this variable was called positive traditional practices-nature conservation relationship (i.e. Do you think that some traditional practices can have a positive effect on nature conservation?) Responses to each question were averaged and a point was added to the score when the species and interaction were clearly explained.

Perceptions of landscape change These perceptions were evaluated by asking whether respondents perceived changes on the landscapes, ecosystems, or species during their experiences at the study site measured on a 3-point Likert scale with one additional point assigned for distinct concepts identified. The resulting variable was called landscape change.

Perceptions of ecosystems vulnerability and ecosystem importance for biodiversity and humanwell-being Respondents were asked to assess the relevance of the predominant ecosystem types of the study site ( $\mathrm{n}=11$; Table 2 in SM) (Albacete 2015), using a Likert scale ranging from 1 (irrelevant) to 10 (highly relevant). To do this, respondents first assessed the relevance of each ecosystem type for (1) biodiversity and nature conservation importance and then for (2) human well-being support. The variable names were \#ecosystem name\# biodiversity value and \#ecosystem name\# human well-being value (e.g. \#holm oak forest\# biodiversity value). Additionally, respondents were asked to identify the ecosystem perceived as most valuable for their role in biodiversity and nature conservation support and the ecosystem perceived as most valuable for their role for human well-being support $(\mathrm{n}=91)$. Finally, respondents were asked to identify which two ecosystem types would be the most vulnerable to threats and impacts in the study site (each ecosystem was coded as 1 for presence and 0 for absence).
Data analysis

Three phases of analysis were conducted. First, correlations between parameters and ecological knowledge systems were estimated by using a nonparametric Spearman's correlation test. Correlations within ecological knowledge systems were also calculated. A comparison of mean perceptions of ecosystem service provision was estimated with a relatedsamples Wilcoxon Signed Rank test. Second, a partial least squares path model was used to test the hypothesized causal relationships between respondent characteristics, knowledge, and perceptions. Third, an ordination of scores for perceptions of ES and landscape vulnerability (i.e. impacts) in relation to ecological knowledge and other predictors was applied to identify the major themes and reduce overall complexity in the variables.

\section{Correlations of parameters and mean comparisons}

A non-parametric Spearman's correlation test was used to explore positive and negative bivariate associations among study variables (i.e. resident characteristics and perceptions with SEK, LEK and EK). Pairwise mean comparisons for perceived importance of the three categories of ES were assessed with a related-samples Wilcoxon Signed Rank test. The correlations and mean comparisons were estimated using SPSS version 26 (Tables 4 and 8 respectively in $\mathrm{SM})$.

Cause-effects between latent and observed variables

A non-parametric path modelling regression technique, Partial Least Square (PLS) structural equation model, was used to examine hypothesized relationships informed by our exploratory analysis using correlations. PLS path modelling has been extensively applied in the social sciences (e.g., marketing) (Hair et al. 2011) and is increasingly used in ecological research (Peppler-Lisbach et al. 2015). This modelling technique is useful for exploring direct and indirect relationships between latent (i.e. unobserved) and manifest (i.e. observed) variables, determining the strength of relationships among multiple dependent variables and estimating the predictive capacity of models. The PLS model was used to test how highly associated parameters of socio-demographics, trip 
characteristics, engagement with the nature, and the urban-rural gradient predicted ecological knowledge. These variables in turn were tested to predict perceptions of: (1) ES provision, (2) impacts on ecosystems (i.e. landscape vulnerability), (3) landscape change and (4) human-nature relationships. The analysis was conducted using the software "Smart-PLS V2" (Ringle et al. 2005). To evaluate goodness-of-fit, we confirmed that the average variance extracted (AVE) values greater than 0.50 and composite reliability (CR) values were greater than 0.70 , indicating convergent validity and internal consistency, respectively. Also, indicator variables displaying factor loadings below 0.70 were removed from analysis (Hair et al. 2011). A bootstrapping test including 10,000 runs $(n=161)$ was conducted to determine the significance of regression coefficients (Hair et al. 2011).

\section{Ordination of perception variables}

The correlation structure among ES and vulnerability perceptions was analysed using a principal component analysis (PCA) (Quintas-Soriano et al. 2019). The PCA identified the main associations among variables and disentangled potential bundles of perceived ecosystem service provision in relation to ecological knowledge to reduce complexity in the dataset. Prior to calculating the PCA, data on perceptions were normalized to unit vector length - that is, the analysis focused on the relative weights of perceptions per respondent. To explicitly test for the influences of ecological knowledge and explanatory variables and to yield a minimum set of those variables explaining the patterns of perceptions best, we additionally performed a redundancy analysis (RDA). PCA and RDA were calculated using the package vegan 2.5-2 (Oksanen 2018) within the R (3.6.1) environment ( $R$ Core Team 2018).

\section{Results}

Characteristics of respondents

Most respondents lived in municipalities with fewer than 10,000 inhabitants (83\%). Seventy six percent of the respondents were between the ages $26-65$ years, while the remainder were 18-25 years (18\%) and over $65(6 \%)$. The respondent average age was 45.4 years
(Standard Deviation $(S D)=16.3)$, aligning with the population in the study site (mean age $=41.9$ ). There were more females $(60 \%)$ than males $(40 \%)$ included in our sample (study site: $52 \%$ women and $48 \%$ men) and $10 \%$ reported involvement in environment-related professions. Half of respondents stated to hold or being in the process of acquiring a higher education degree (i.e. university related studies), which is higher than educated attained by the population in the study site $(21 \%)$ (Albacete 2015) (Table 5 in SM).

\section{Ecological knowledge}

We observed variation in levels of LEK and SEK with standardized SEK scores ranged from 0.3 to 4.4 (Mean $(M)=1.55, S D=0.68)$ and LEK scores ranged from 0.0 to $3.6(M=1.08, S D=0.74)$. According to descriptive statistics, LEK was slightly left skewed (Skewness: 0.879) while SEK was more centralized (Skewness: 0.665). The SEK score was normally distributed (Kolmogorov-Smirnov (KS) test statistic $=0.049 ; p=0.20)$ and LEK was not normally distributed (KS test statistic $=0.098 ; p<0.01)$. To assess the potential influence of a sample biased toward highly-educated respondents for the distributions of SEK and LEK scales, we run a test of normality with an aleatory sub-sample containing a significant lower number of respondents who stated to have a high-education degree (50\% less, 43 Respondents, $\mathrm{n}=118$ ). These results show the same pattern for SEK (i.e. KS test statistic $=0.051 ; p=0.20 ; M$ $=1.34, S D=0.54$ ) and LEK (i.e. KS test statistic $=0.130 ; p<0.01 ; M=0.83 ; S D=0.59$ ) (Table 6 in SM).

\section{Correlations and mean comparisons}

Results of the bivariate Spearman's correlations showed significant associations between parameters (Fig. 2 and Table 4 in SM).

\section{Associations between knowledge systems}

Measures of SEK and LEK were highly positively correlated $\left(\mathrm{n}=161, r_{s}=0.68 ; p \leq 0.01\right)$. To assess the potential effect of a sample biased toward educated respondents we ran a partial correlation with education as controlling factor. The result showed a highly similar pattern $(\mathrm{n}=161$; Partial correlation 

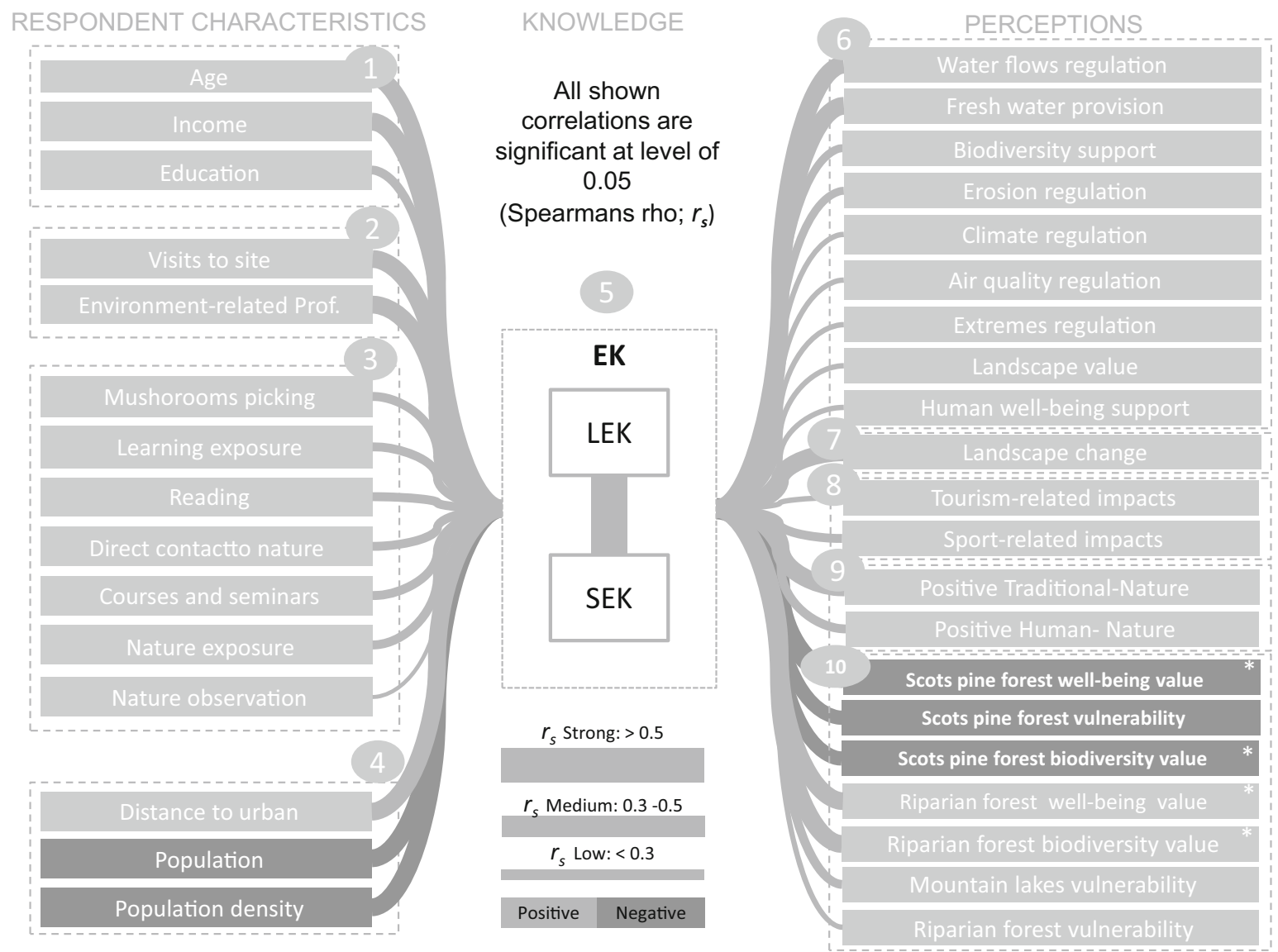

Fig. 2 Associations based on Spearman's correlation analysis. Only significant correlations are shown $(\mathrm{p} \leq 0.05)$. The strength of relationships is indicated by the line width joining parameters ( $r_{s}$ Spearman's rho Correlation Coefficient). Positive correlations are indicated with light pale grey-coloured lines, negative correlations with dark grey-coloured lines. (1) Socio-demographics; (2) Trip characteristics; (3) Engagement with nature; (4) Urban-rural gradient; and (5) Ecological knowledge (EK) (Sum of LEK and SEK scores, local and scientific ecological

coefficient $=0.66 ; \mathrm{p}<0.01)$. Additionally, a correlation test between SEK and LEK for a sub-sample excluding all highly-educated respondents indicated that level of education did not influence variation in the association between SEK and LEK ( $\mathrm{n}=76$; $r_{s}=0.66 ; \mathrm{p}<0.01$. In many cases (94 from 116 cases; $82 \%$ ), both SEK and LEK were associated with respondent characteristic and perception parameters in similar ways (e.g. association between age and LEK, and age and SEK respectively: $r_{s}=0.37$ and $r_{s}=0.37$ $p \leq 0.01$ ) (Table 4 in $\mathrm{SM}$ ). Therefore, to evaluate associations, responses and effects of a global knowledge, respectively). Respondent perceptions of: (6) ES provision; (7) landscape change, (8) landscape vulnerability, (9) human-nature relationships and (10) ecosystems vulnerability and capacity for supporting biodiversity and human well-being (Sample size was $n=161$ for all variables except for variables measuring perceived capacity of ecosystems for supporting biodiversity and human well-being, $\mathrm{n}=91^{*}$. Only 91 respondents answered these questions)

parameter of ecological knowledge (EK) the previous two scores (SEK and LEK) were collapsed into one variable.

\section{Associations between respondent characteristics and $E K$}

Age, income and education level were positively correlated with EK, whereas years living in the site and gender were not significantly correlated with EK (Fig. 2). Seminars and courses, direct contact to nature and reading were forms of learning 
Table 1 Results of partial least square structural equation model including mean values, SD, and standardized regression coefficients ( $\beta)$

\begin{tabular}{|c|c|c|c|}
\hline Latent and observed variables & Mean (SD) & $\begin{array}{l}\text { Direct effects on ecological } \\
\text { knowledge }(\beta)\end{array}$ & $\begin{array}{l}\text { Direct effects of ecological } \\
\text { knowledge on perceptions }(\beta)\end{array}$ \\
\hline \multicolumn{4}{|l|}{ Predictor variables } \\
\hline $\begin{array}{l}\text { Socio demographic characteristics } \\
\quad(\mathrm{AVE}=0.64, \mathrm{CR}=0.78)\end{array}$ & & 0.32 & \\
\hline Age & $45.33( \pm 16.13)$ & & \\
\hline Income & $1.84( \pm 1.10)$ & & \\
\hline $\begin{array}{l}\text { Trip characteristics }(\mathrm{AVE}=0.58, \\
\mathrm{CR}=0.74)\end{array}$ & & 0.23 & \\
\hline Visits to the site & $4.32( \pm 1.66)$ & & \\
\hline Environment-related profession & $0.13( \pm 0.34)$ & & \\
\hline $\begin{array}{l}\text { Engagement with nature }(\mathrm{AVE}=.53 \text {, } \\
\mathrm{CR}=0.68)\end{array}$ & & 0.27 & \\
\hline Learning exposure & $3.64( \pm 1.59)$ & & \\
\hline Nature exposure & $5.14( \pm 2.15)$ & & \\
\hline Urban-rural gradient & & 0.23 & \\
\hline Distance to urban center & $18.50( \pm 17.11)$ & & \\
\hline \multicolumn{4}{|l|}{ Ecological knowledge } \\
\hline \multicolumn{4}{|l|}{$\begin{array}{l}\text { Ecological knowledge }(\mathrm{AVE}=0.84 \\
\left.\quad \mathrm{CR}=0.91, \mathrm{R}^{2}=0.50\right)\end{array}$} \\
\hline Local ecological knowledge & $1.08( \pm 0.74)$ & & \\
\hline Scientific ecological knowledge & $1.55( \pm 0.68)$ & & \\
\hline \multicolumn{4}{|l|}{ Perceptions of } \\
\hline $\begin{array}{l}\text { Ecosystem services }(\mathrm{AVE}=0.82, \\
\left.\mathrm{CR}=0.90, \mathrm{R}^{2}=0.13\right)\end{array}$ & & & 0.35 \\
\hline Water flow regulation & $8.84( \pm 1.87)$ & & \\
\hline Fresh water provision & $8.98( \pm 1.88)$ & & \\
\hline Landscape change $\left(\mathrm{R}^{2}=0.12\right)$ & $2.15( \pm 1.42)$ & & 0.35 \\
\hline Human-nature relationships $\left(\mathrm{R}^{2}=0.17\right)$ & & & 0.40 \\
\hline $\begin{array}{l}\text { Traditional practices-nature } \\
\text { conservation }\end{array}$ & $1.30( \pm 1.06)$ & & \\
\hline $\begin{array}{l}\text { Landscape vulnerability }(\mathrm{AVE}=0.75 \text {, } \\
\left.\qquad \mathrm{CR}=0.86, \mathrm{R}^{2}=0.07\right)\end{array}$ & & & 0.27 \\
\hline Sport-related impacts & $6.94( \pm 2.56)$ & & \\
\hline Tourism-related impacts & $8.69( \pm 1.69)$ & & \\
\hline
\end{tabular}

Metrics for model consistency include average variance extracted (AVE) and composite reliability (CR) scores

significantly and positively correlated with EK. Mushroom picking and nature observation were the only nature exposure activities significantly and positively correlated with EK. Residents living in more urbanized areas were less likely to have high levels of EK as distance to urban center was positive correlated with EK. Both population size and population density were negatively correlated to $E K$.

\section{Associations between EK and ES perceptions}

Though weak, results indicated EK was significantly and positively correlated with landscape value, indicating respondents with higher levels of knowledge were more likely to be attuned to the provision of multiple ES. Specifically, EK was strongly correlated with perceived importance of water-related ES and 


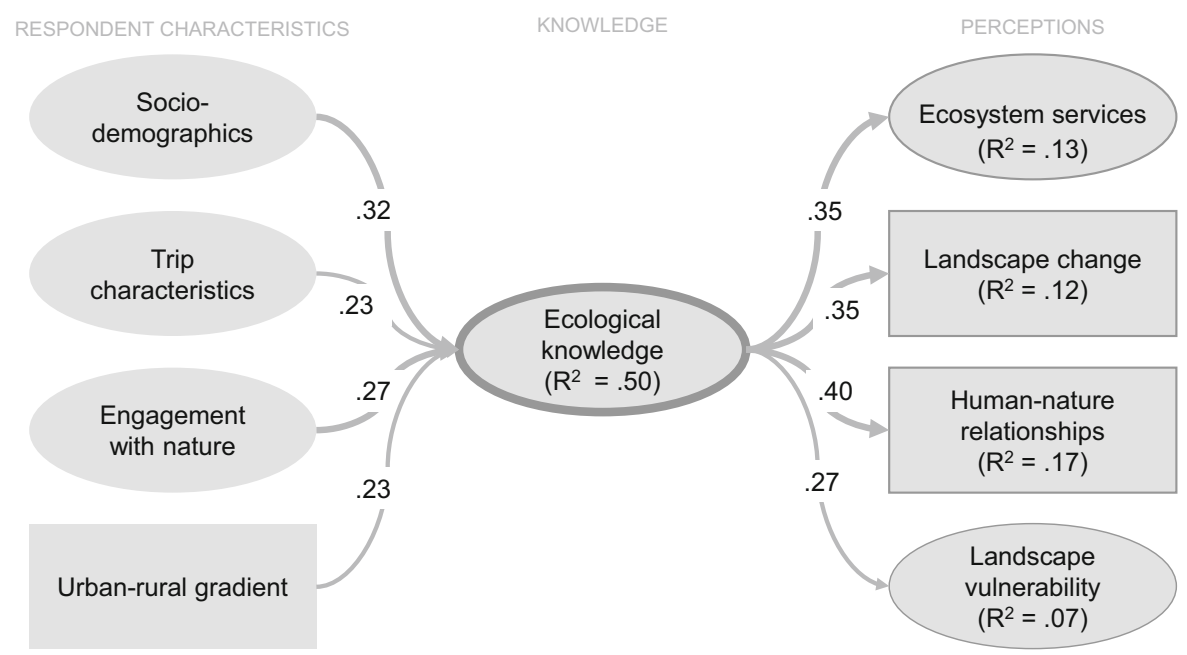

Fig. 3 PLS path model results showing relationships among study variables $(\mathrm{n}=161)$, including three latent predictors and one observed predictor (all exogenous variables) that influence the latent variable, ecological knowledge, which then explain

most regulating ES including water flows, erosion prevention, climate, extremes and air quality. Freshwater provision was the only significant provisioning service positively associated with EK. None of the cultural services (i.e. sense of place, recreation, aesthetic or spiritual value) were significantly correlated to EK despite high mean values for cultural services among respondents $(M=8.0, S D=1.0)$.

The results also highlighted a positive association between EK and perceptions of landscape change. The highest correlations between EK and ecosystems perceived capacity to support biodiversity and nature conservation corresponded to riparian forest, Ilex aquifolium forest, fragmentary rocky rubbles ("Canchales") and mountain lakes and peatlands (Table 4 in $\mathrm{SM})$. However, there was no correlation between EK and other ecosystems' perceived capacity such as scots pine forests, nor valley pastures. When asked to identify only the two most relevant ecosystems, one for biodiversity and nature conservation and later for supporting human well-being, only riparian forest showed significant positive correlation with EK, for both biodiversity support and human well-being. Finally, perceived vulnerability of two water-dependent ecosystems, mountain lakes and riparian forests, were positively correlated to EK. Contrarily, perceived vulnerability of scots pine forest was negatively correlated to EK. When assessing how respondents perceived the relevance of impacts, the resident perceptions of two latent variables and two observed variables. The standardized beta coefficients and $\mathrm{R}^{2}$ values are displayed on latent (ovals) and observed (rectangles) variables (endogenous variables)

only correlations identified as significant were perceptions of sport-related impacts and tourism-related impacts A positive correlation between EK and perceived benefits of traditional practices on nature conservation relationship, and indicated acknowledgment of the benefits from some human activities on wild species (e.g. positive human-nature relationship) was found.

\section{Comparisons between perceived ES categories}

The Related-Samples Wilcoxon Signed Rank Test revealed that regulating services $(M=8.75 ; S D=1.29)$ were perceived as significantly more important than cultural $(M=8: 00 ; S D=1.52)$ or provisioning $(M=$ $8.00 ; S D=1.36)(\mathrm{n}=161$; Test Statistic: 2384.5 $p<0.01$; Test Statistic: 2106; $p<0.01$ ) (Tables 3 and 8 in SM).

Path modelling

All latent variables had values greater than or equal to 0.5 and 0.7 for average variance extracted (AVE) and composite reliability (CR) (Hair et al. 2011) (Table 1). In response to exploratory analysis involving a stepwise elimination of non-significant pathways and indicator variables from the a priori hypotheses, the final model was obtained (Fig. 3 and Table 1). Education was not retained in socio-demographics latent 
Fig. 4 Results from PCA analysis. The bi-plot shows the relationships between stakeholders' perceptions towards particular ES and ecological impacts and their correlation to ecological knowledge and sociodemographic variables. Displayed are axis 1 scores (14\% of total variance) vs. axis 2 scores ( $11 \%$ of total variance). Detailed legend: orange: regulative ES; blue: cultural ES; green: ecological impacts; grey: correlations with ecological knowledge and respondent characteristics; dots: male respondents, circles: female respondents red: provisioning ES;

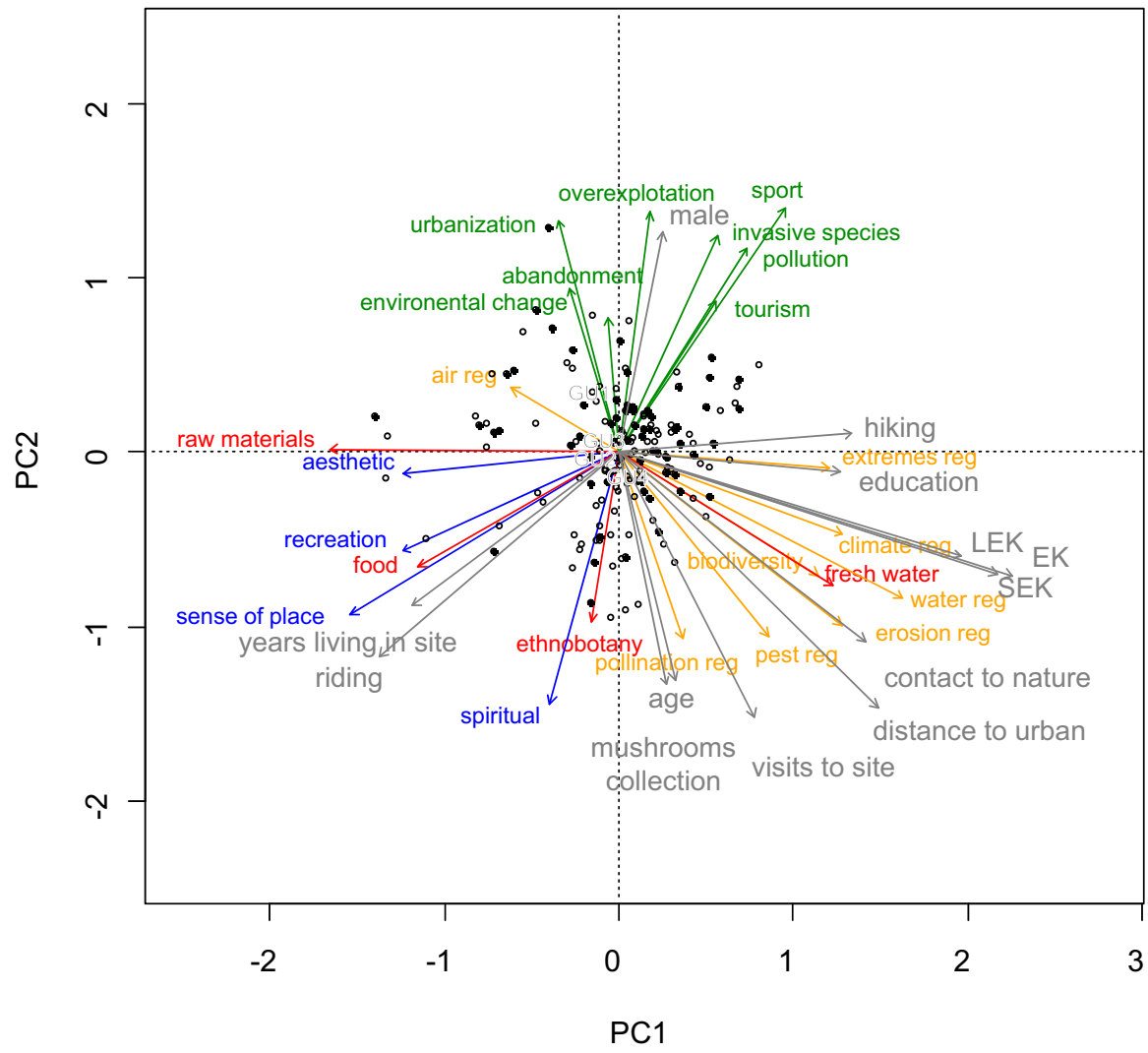

variable. Only distance to urban center was kept in the rural-urban gradient set of variables. With respect to EK and its influence on subsequent dependent variables, for the latent variable ecosystem services only water flow regulation and freshwater provision were retained, and in landscape vulnerability only sport and tourism-related impacts were retained.

Results from the path model showed strong predictive power, in that a high but variable degree of variance in all endogenous constructs was accounted for by predictor variables. The final model included only significant effects at a level of $\mathrm{t}=2.58$ (Hair et al. 2011). Specifically, EK was predicted by socio-demographics $(\beta=0.32)$, trip characteristics $(\beta=0.23)$, engagement with nature $(\beta=0.27)$ and urban-rural gradient (distance to urban center) $(\beta=0.23)$. EK was a moderate and weak predictor of the final dependent variables in the path model, including perceived parameters of ecosystem services $(\beta=0.35)$, landscape change $(\beta=0.35)$, human-nature relationships $(\beta=0.40)$, landscape vulnerability $(\beta=0.27)$. As shown in Fig. 3 , the $R^{2}$ values of these endogenous variables ranged from 0.07 to 0.13 .

\section{Ordination of data}

Results from the PCA identified two gradients reflecting main correlation patterns among the study variables (Fig. 4 and Online Table 7). Three main groups of associations were detected: one bundle captured all perceptions of provisioning services except freshwater and all cultural ES, a second bundle covered all perceptions of regulating services except air regulation, and a third bundle covered all perceptions of impact-related variables (e.g. tourism and sports, environmental change, and invasive species).

Axis 1 was positively correlated with EK, education, age, visits to site, distance to urban areas, hiking, contact to nature and plants and mushrooms collection, while negatively correlated with years living in the site and riding. More knowledgeable respondents emphasized regulating ES and fresh water supply, the others focussed on cultural services and the most provisioning services (i.e. Perceptions trade-off 1). Axis 2 was positively correlated to gender, age, distance to urban and geographic unit. Urban male respondents, from geographical unit 1 (Segovia 


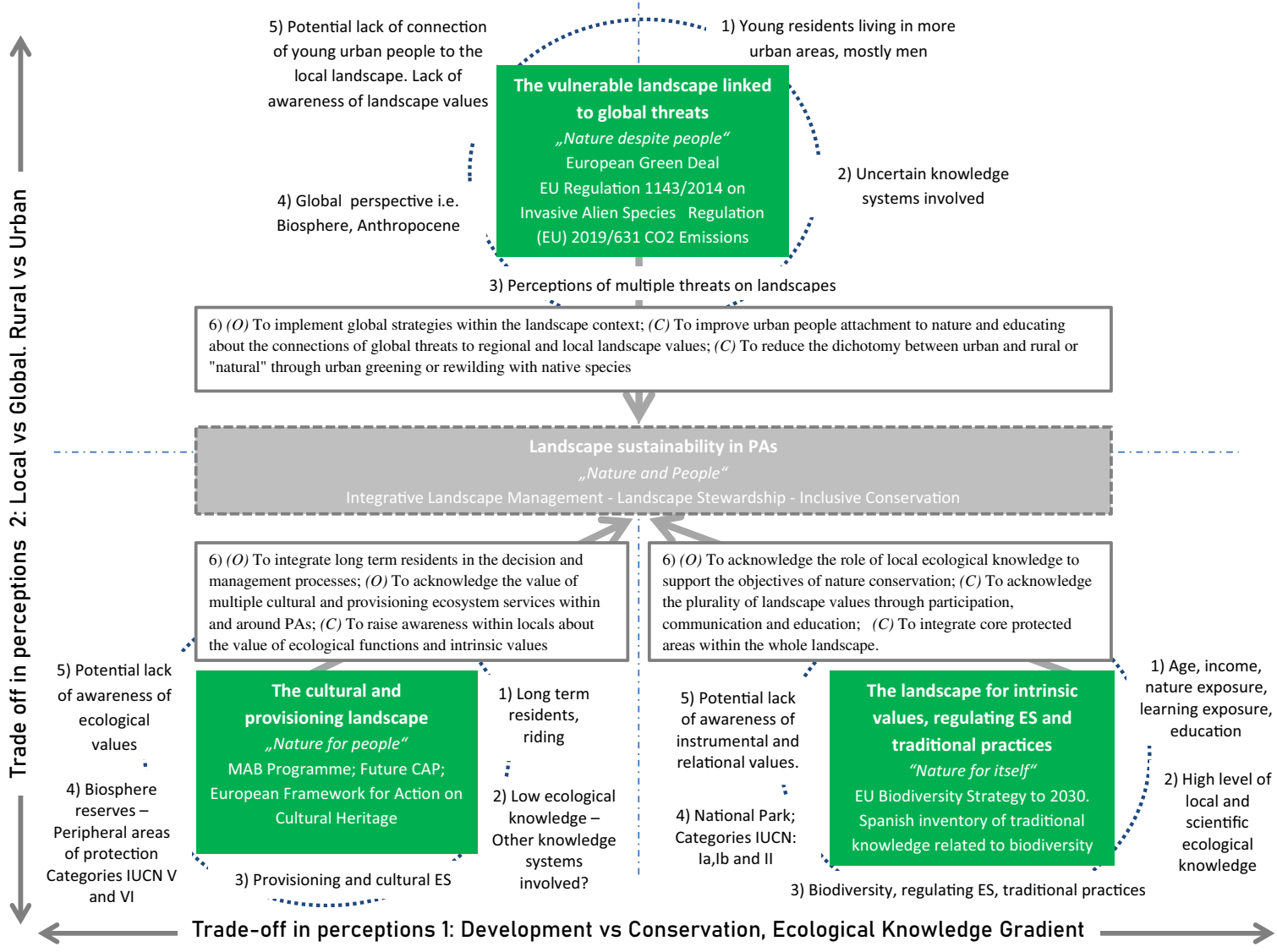

Fig. 5 The figure represents a conceptual model showing three elicited social representations or visions about the landscapes of Sierra de Guadarrama (Spain) that emerged in our findings. These visions are explained by (1) resident's characteristics, (2) ecological knowledge and (3) perceptions of ES and impacts on the landscape. Further, (4) potential local PAs related to the resulting visions are shown, (5) potential challenges associated

municipality), tended to emphasize regional impacts and were less aware of the importance of regulating services (except air quality), provisioning services (except raw materials) and cultural services (i.e. Perceptions trade-off 2). Based on the associated parameters and previous work (Quétier 2010), we categorized the original bundles of perceived ES and impacts into three different social representations, namely visions, of how local residents perceive the landscapes of Sierra de Guadarrama. These three visions were identified based on location in different sections of the two-axes PCA: (1) The landscape for intrinsic values, regulating ES and traditional practices; (2) The cultural and provisioning landscape and with trade-offs in perception and (6) implications for management are highlighted. Every vision is related to major nature conservation strategies identify by Mace (2014) (e.g. Nature for itself). These visions also link to major international and regional policies or strategies in environmental protection, nature conservation or rural development. (O) Opportunity; (C) Challenge

(3) The vulnerable landscape linked to global challenges (Fig. 5).

Redundancy analysis additionally allowed us to reduce the set of correlating predictor variables to a minimal adequate model by explicitly testing the influence of variables and their combination on the multivariate perception pattern. The minimal adequate model achieved by backward stepwise variable selection contained the explanatory variables of EK, namely gender, distance to urban center and years living in the site (Online Table 9 and Fig. 6 in SM). Axis 1 and Axis 2 from RDA were widely similar to PCA. 


\section{Discussion}

This research aimed to address a prominent challenge of accounting for different forms of ecological knowledge alongside perceptions of landscapes and their ES to inform about how sustain social-ecological systems within and surrounding PAs. Our results confirmed most of our predictions; however some deviations to the expectations were found. For instance, both SEK and LEK were strongly associated, and, in most cases, correlated with similar parameters, creating ambiguity between them. Important nuances were found on how increasing ecological knowledge influences perceived ES, perceived landscape impacts or perceived ecosystem vulnerability. Unexpected results were found in relation to which resident characteristics and behaviours were associated with higher ecological knowledge, as EK was not related to long-term residents but to other resident traits (i.e. education, income, age or distance to urban centres). Finally bundles of perceived ES and impacts showed interesting patterns that were explained by distinctive resident profiles.

Interactions between ecological knowledge systems

While previous research has frequently positioned scientific and local knowledge to be conceptually distinct (e.g. Reid et al. 2006; Tengö et al. 2017), our results showed a high level of correspondence between these two knowledge systems. This finding implies that there are relational dynamics across knowledge types, which here may be attributed to the interactions between residents, newcomers in search of ES and scientists in the Sierra de Guadarrama since the midlate nineteenth century (Vías 2011). Further, important questions were raised about how knowledge of biodiversity, ecosystems and nature conservation should be measured and conceptualized in future research, particularly, in Western contexts where local communities generally have high access to naturerelated experiences and hybrid knowledge systems, including traditional practices, are maintained consciously and economically incentivized (Aswani et al. 2018). Rather than viewing local and scientific knowledge about ecosystems as mutually exclusive, researchers might consider these knowledge systems as interdependent and highly permeable (Agrawal
1995). Nevertheless, the possible existence of this process might not prevent that much of the local and traditional ecological knowledge is being eroded or transformed due to socio-economic and cultural changes and loss of its use in practice, not only in western societies (Gómez-Baggethun et al. 2010), but also in areas and continents where changes in values, economy, lifestyles are even more dramatic driven by globalization, modernization, and market integration (Díaz et al. 2019; Aswani et al. 2018).

Perceptions of landscapes in relation to ecological knowledge

Contrary to other studies and contexts where both provisioning and cultural services have generally been perceived as more important than regulating services (Oteros-Rozas et al. 2014), our results indicated that regulating services were most important, as shown in previous works performed in PAs (Martín-López et al. 2012). This may be due to the particular context of the SG, constituting a complex system of PAs and located in close proximity to a large metropolitan area (ca. 5.5 million inhabitants), with more environmentally oriented newcomers who may place higher value and hold more knowledge about the corresponding ES.

In response to recent calls for research that integrates multiple values of nature into conservation policy and practice (Mace 2014; Tallis and Lubchenco 2014; Kenter et al. 2019), this study provided insight into how ecological knowledge (consisting of both local and scientific knowledge) related to perceptions of ecosystem service provision, ecosystem change and vulnerability, human-nature relationships, and environmental impacts. The correlation, path model, and the ordination results revealed significant and clear patterns of positive relationships among ecological knowledge and many of the study parameters measuring perceptions on landscapes. Specifically, the set of variables associated with EK is subsequently reduced in the regression techniques to a lower number of predictors i.e. path-model and redundancy analysis, as in these analyses the relationships highlight potential candidates for cause-effects patterns. It is important to highlight the positive association between more knowledgeable residents and the perceived importance of regulating services (both in the correlations and ordination) and in particular services related to water (e.g. water regulation and fresh water 
provision) (correlations and the path model). Besides, EK was significantly and positively correlated with perceived vulnerability of strongly water-dependent ecosystems (e.g., riparian forest, mountain lakes and peat-land), revealing how significant water is as an asset in this particular context (Albacete 2015). In general, EK was positively related to the perceived importance of several ecosystems that support biodiversity and human-well-being, however, ecological knowledge was negatively correlated with perceptions of scots pine forest vulnerability and its capacity to support biodiversity and human well-being despite the socio-cultural, historic and biogeographic significance of this ecosystem in SG (Vías 2011; Albacete 2015). Results from the path model showed that as knowledge increased so too did the intensity of residents' perceptions of a social-ecological system surrounding the SG. However, little variation was explained for the relationship between EK and perceptions (both in the path model (R2: 0.7-0.13) and the ordination methods (25\%)) which may be because: (1) the complexity of the perceived system; or (2) difficulties in detecting patterns in the general public due to variation among individual worldviews, values, experiences, and aspirations compared to focused stakeholder groups that tend to express normative visions (Iniesta-Arandia et al. 2014; Cebrián-Piqueras et al. 2017; QuintasSoriano et al. 2019). Corroborating these findings, previous studies have found that self-reported knowledge accounts for variation in how stakeholders perceive biodiversity and respond to degradation within PAs (van Riper et al. 2017). Considering the distinguishable characteristics of particular constituencies is a critical process for ensuring the relevance of research and legitimacy of policy outcomes that emerge from stakeholder engagement. Our results provide important theoretical insights into the relationships among knowledge, values, and placebased experiences, and, as discussed below, we show that the interface between knowledge and landscape perceptions is more complex.

\section{Explaining ecological knowledge through resident} characteristics

Greater knowledge about biodiversity, ecosystems or practices and uses of biodiversity was predicted by socio-demographics, trip characteristics, engagement with nature and the rural-urban gradient. Increasing levels of ecological knowledge were highly related to higher income, age, education and a variety of forms for contacting and learning about nature or environment-related professions, but not related to gender or the years living in the site, contrary to previous results found in other systems (Iniesta-Arandia et al. 2014). The positive association between age, income and education coincides with previous landscape planning studies showing that older, wealthier and more formally educated participants are more likely to engage in participatory discussions about the environment (McLain et al. 2017). Further, our findings revealed that activities such as mushroom picking and nature observation may be important experiences for developing a deeper understanding of the local surrounding natural system. However, these practices and learning processes, as suggested here, do not necessary need to be related only to indigenous people as we understand from a western perspective (Díaz et al. 2018) because supplementary learning (i.e. reading or professional contact to nature) might add additional layers of knowledge. The weak association between knowledge and length of residence in the area is revealing. Previous research suggests that residents with more self-reported knowledge of places have lived in a given area for a longer period of time (Raymond and Brown 2007), but knowledge of places does not always translate into ecological awareness and willingness to conserve nature. Indeed, in some cases longer-term residents are less likely to conserve biodiversity than newcomers to an area (Raymond and Brown 2011). We extend these debates by showing that contact with and learning about nature have more important roles than years living on place when seeking more local or scientific understandings of ecological functions and processes.

Resident visions, tensions and management implications

The ordination results revealed that both local and scientific ecological knowledge were not aligned with perceptions of non-material benefits one obtains from the landscape. Given that ecological knowledge was not related to perceived cultural ES as expected (Berthet et al. 2019), awareness and previous experiences were not precursors to the enjoyment of perceived non-material benefits of nature. For instance, the correlations and path model analysis 
revealed how tourism and sport were perceived as threats by more knowledgeable residents. Nevertheless, knowledgeable residents positively perceived the benefits of some human uses and traditional practices on nature conservation, implying that transmission of knowledge across generations is core to ecological understanding of biodiversity. Besides, knowledgeable respondents generally practiced specific cultural activities i.e. plants and mushrooms collection, nature observation or hiking.

Our study revealed three major social representations or visions that were related to residents' characteristics. These visions highlight potential tensions that may arise between local communities and the different landscape management strategies considered (Fig. 5). For instance, respondents with high LEK and SEK were more focused on regulating services and intrinsic values, but also acknowledged positive effects of humans to nature (i.e. traditional practices). This finding can guide landscape management decisions to include the acknowledgment and integration of LEK to improve understanding of nature and its conservation. Challenges raised by this view are potential tensions with nearby local communities, lack of awareness for instrumental and relational values and a lack of connectivity with other natural and semi natural areas. This view can be well represented by more restrictive land use regulations i.e. National Park, by the new EU Biodiversity Strategy 2030 or by national initiatives such as the Spanish Inventory of Traditional Ecological Knowledge associated with Biodiversity. In contrast, long term residents with lower levels of LEK and SEK and lower formal education level, but higher landscape attachment may prefer a landscape that provides provisioning and cultural services. This vision aligns with a less restrictive approach to managing the study site (e.g. biosphere reserves). Finally, young residents from more urban areas revealed a lack of connection with the nearby natural and rural areas and a lack of awareness of multiple landscape values. However, these individuals were sensitive to the multiple threats on the landscape such as climate change, alien species, or pollution. Actions to improve urban residents' attachment to landscapes and nature will require greater attention to increasing environmental education and reducing the dichotomy between urban-rural and urban-natural to implement global strategies within the landscape context. These findings indicate that multiple interpretations of PAs can support nature conservation and landscape values in different ways. Our results highlight the need of an inclusive approach for understanding and accounting for the plurality of worldviews, perceptions, and knowledge systems to achieve landscape sustainability within and around PAs (Mace 2014; Palomo et al. 2014; Bennett 2016; Díaz et al 2018). The diversity of PA types and complementary management systems in SG indicate that there is a baseline for weaving and accounting the presented residents views about the landscapes. However, PA decision-makers should ensure communication strategies, participatory processes and educational programs tailored to specific contexts that account for a variety of knowledge systems and interpretations of nature to avoid potential tensions we have highlighted here.

\section{Caveats}

Our findings include a few caveats that warrant explanation. First, the scales used to measure ecological knowledge have not been tested outside of this study which introduces the risk of misrepresenting stakeholders who believe their knowledge is grounded in different human-nature relationships, languages and traditions. Evaluating knowledge using the scales adopted here may also fail to capture the inherent complexity and nuances in knowledge systems and related body of practices and experiences. Further, recent global assessments are increasingly recognising the importance of plurality in valuing nature (Díaz et al. 2019). Future research would benefit from representing the diversity of ecological knowledge systems in path models. Second, while learning was a parameter in our model, we did not consider the feedbacks among learning, ecological knowledge, and landscape perception as a dynamic process of social interaction (Reed et al. 2010). Future research could assess the effects of social learning and other communications processes on variation in ecological knowledge, visions, and values for PA management. Research that explores the role of landscape perceptions as an agent connecting knowledge systems and individual and collective practices and actions will be crucial for increasing social-ecological resilience in PAs and broader social-ecological systems (Bennett 2016). Finally, we argue that acknowledging the relationships between experiences, knowledge, and 
perceptions of benefits and threats in PAs by local communities can inform processes aiming at landscape sustainability (Berthet et al. 2019; Liao et al. 2020).

\section{Conclusions}

Are scientific and local knowledge systems distinctive enough? Can ecological knowledge explain perceptions about landscapes? Can this knowledge be predicted by stakeholder's characteristics such as behaviour, socio-demographics or urban-rural gradient? Our results provide insight into answering these questions, in the context of municipalities within the Sierra de Guadarrama. These findings revealed relationships between respondent characteristics and local and scientific ecological knowledge. We found evidence of an interdependent relationship between both local and scientific knowledge systems as qualified by similar relationships between each system and respondent characteristics.

Despite finding patterns indicating that higher levels of ecological knowledge may influence perceptions of ecosystem service provision and ecosystems vulnerability (e.g. regulating services or water related services and ecosystems), our research also acknowledges that perceptions about the value of both tangible (e.g., provisioning services) and non-tangible (e.g., cultural services) benefits and threats on landscapes must be linked to other experiences, knowledge systems, values or socio-economic characteristics to reveal multiple social representations of landscapes. Considering the diversity of these worldviews needs to be tailored to management interventions and strategies to avoid conflict and relax tensions.

This research provides insight into the benefits and limitations to weaving apparently distinctive knowledge system for landscape sustainability and nature conservation in protected areas. Diverging attitudes and priorities towards the conservation and use of ecosystem services can lead to conflicts. We argue that understanding the causes underpinning these divergences, including ecological knowledge, perceived benefits and socio-demographics, can help to identify which knowledge systems or pockets of knowledge are relevant and vulnerable. Our insights on the interplay of scientific and local ecological knowledge can inform sustainable landscape management strategies and plans in PAs.

Acknowledgements This paper was supported by the ENVISION project, funded through the 2017-2018 Belmont Forum and BiodivERsA joint call for research proposals, under the BiodivScen ERA-Net COFUND programme, and with the support of national funders (German Federal Ministry of Education and Research, Grant Number: 01LC18064, National Science Foundation under Grant No. 1854767). We want to thank the valuable support of the staff of the Spanish National Centre of Environmental Education (CENEAM) and the local collaborators who conducted interviews with local residents. IRM (Grant No. RYC-2015-17676). EOR (Grant No. IJCI-2017-34334).

Open Access This article is licensed under a Creative Commons Attribution 4.0 International License, which permits use, sharing, adaptation, distribution and reproduction in any medium or format, as long as you give appropriate credit to the original author(s) and the source, provide a link to the Creative Commons licence, and indicate if changes were made. The images or other third party material in this article are included in the article's Creative Commons licence, unless indicated otherwise in a credit line to the material. If material is not included in the article's Creative Commons licence and your intended use is not permitted by statutory regulation or exceeds the permitted use, you will need to obtain permission directly from the copyright holder. To view a copy of this licence, visit http://creativecommons.org/licenses/by/4.0/.

Funding Open access funding provided by Projekt DEAL.

\section{References}

AEMET (2019) Data from the Navacerrada Pass Station for Years 1971 to 2000. https://www.aemet.es/es/ serviciosclimaticos/datosclimatologicos/ valoresclimatologicos? $\mathrm{l}=2462 \& \mathrm{k}=\mathrm{mad}$

Agrawal A (1995) Dismantling the divide between indigenous and scientific knowledge. Dev Change 26:413-439

Albacete L (2015) Percepción de La Población Local Sobre El Parque Nacional de La Sierra de Guadarrama y Su Medio Físico. Organismo Autonomo de Parques Nacionales, Madrid

Alessa L, Bennett SM, Kliskey AD (2003) Effects of knowledge, personal attribution and perception of ecosytem health on depreciative behaviors in the intertidal zone of Pacific Rim National Park and Reserve. J Environ Manage 68:207-218

Apio A, Umuntunundi P, Lerp H, Bierbach D, Plath M, Wronski $\mathrm{T}$ (2015) Persistence of two small antelope species in the degraded mutara rangelands (Akagera ecosystem) based on pastoralists' and farmers' perceptions. Hum Ecol 43:613-620 
Aswani S, Lemahieu A, Sauer WHH (2018) Global trends of local ecological knowledge and future implications. PLoS ONE. https://doi.org/10.1371/journal.pone.0195440

Bennett NJ (2016) Using perceptions as evidence to improve conservation and environmental management. Conserv Biol 30:582-592

Berkes F (1999) Sacred ecology: traditional ecological knowledge and resource management. Taylor \& Francis, Philadelphia

Berthet ET, Bretagnolle V, Lavorel S, Sabatier R, Tichit M, Segrestin B (2019) Applying ecological knowledge to the innovative design of sustainable agroecosystems. J Appl Ecol 56:44-51

Braga HO, Azeiteiro UM, Oliveira HMF, Pardal MA (2017) Evaluating fishermen's conservation attitudes and local ecological knowledge of the European sardine (Sardina pilchardus), Peniche, Portugal. J Ethnobiol Ethnomed. https://doi.org/10.1186/s13002-017-0154-y

Cebrián-Piqueras MA, Karrasch L, Kleyer M (2017) Coupling stakeholder assessments of ecosystem services with biophysical ecosystem properties reveals importance of social contexts. Ecosyst Serv 23:108-115

Coreau A, Guillet F, Rabaud S (2018) The influence of ecological knowledge on biodiversity conservation policies: a strategic challenge for knowledge producers. J Nat Conserv 46:97-105

Díaz S, Pascual U, Stenseke M, Martín-López B, Watson RT, Molnár Z, Hill R, Chan KMA, Baste IA, Brauman KA, Polasky S, Church A, Lonsdale M, Larigauderie A, Leadley PW, Van Oudenhoven APE, Van Der Plaat F, Schröter M, Lavorel S, Aumeeruddy-Thomas Y. Bukvareva E, Davies K, Demissew S, Erpul G, Failler P, Guerra CA, Hewitt CL, Keune H, Lindley S, Shirayama Y (2018) Assessing nature's contributions to people: recognizing culture, and diverse sources of knowledge, can improve assessments. Science 359:270-272

Díaz S, Settele J, Brondízio E, Ngo HT, Guèze M, Agard J, Arneth A, Balvanera P, Brauman K, Butchart S, Chan K, Garibaldi L, Ichii K, Liu J, Subramanian SM, Midgley G, Miloslavich P, Molnár Z, Obura D, Pfaff A, Polasky S, Purvis A, Razzaque J, Reyers B, Roy R, Shin Y, VisserenHamakers I, Willis K, Zayas C (2019) Summary for policymakers of the global assessment report on biodiversity and ecosystem services - unedited advance version. Ipbes. pp 1-39

EUROPARC-España (2019) Anuario 2018 del estado de las áreas protegidas en España. Ed. Fundación Fernando González Bernáldez, Madrid

Frazão-Moreira A, Carvalho AM, Martins ME (2009) Local ecological knowledge also 'comes from books': Cultural change, landscape transformation and conservation of biodiversity in two protected areas in Portugal. Anthropol Notebooks 15:27-36

Gerhardinger LC, Godoy EAS, Jones PJS (2009) Local ecological knowledge and the management of marine protected areas in Brazil. Ocean Coast Manage 52:154-165

Gómez-Baggethun E, Mingorría S, Reyes-García V, Calvet L, Montes C (2010) Traditional ecological knowledge trends in the transition to a market economy: empirical study in the Doñana natural areas. Conserv Biol 24:721-729
Gómez-Baggethun E, Reyes-García V, Olsson P, Montes C (2012) Traditional ecological knowledge and community resilience to environmental extremes: a case study in Doñana, SW Spain. Glob Environ Chang 22:640-650

Gray CL, Hill SLL, Newbold T, Hudson LN, Boïrger L, Contu S, Hoskins AJ, Ferrier S, Purvis A, Scharlemann JPW (2016) Local biodiversity is higher inside than outside terrestrial protected areas worldwide. Nat Commun 7:12306

Hair JF, Ringle CM, Sarstedt M (2011) PLS-SEM: Indeed a silver bullet. J Mark Theory Pract 19:139-151

Heckathorn DD (2011) Comment: Snowball versus respondentdriven sampling. Sociol Methodol 41:355-366

Iniesta-Arandia I, del Amo DG, García-Nieto AP, Piñeiro C, Montes C, Martín-López B (2014) Factors influencing local ecological knowledge maintenance in Mediterranean watersheds: insights for environmental policies. Ambio 44:285-296

Kati V, Hovardas T, Dieterich M, Ibisch PL, Mihok B, Selva N (2015) The challenge of implementing the European network of protected areas Natura 2000. Conserv Biol 29:260-270

Kenter JO, Raymond CM, van Riper CJ, Azzopardi E, Brear MR, Calcagni F, Christie I, Christie M, Fordham A, Gould RK, Ives CD, Hejnowicz AP, Gunton R, Horcea-Milcu AI, Kendal D, Kronenberg J, Massenberg JR, O'Connor S, Ravenscroft N, Rawluk A, Raymond IJ, Rodríguez-Morales J, Thankappan S (2019) Loving the mess: navigating diversity and conflict in social values for sustainability. Sustain Sci 14:1439-1461

Lamarque P, Tappeiner U, Turner C, Steinbacher M, Bardgett RD, Szukics U, Schermer M, Lavorel S (2011) Stakeholder perceptions of grassland ecosystem services in relation to knowledge on soil fertility and biodiversity. Reg Environ Change 11:791-804

Le Saout S, Hoffmann M, Shi Y, Hughes A, Bernard C, Brooks TM, Bertzky B, Butchart SHM, Stuart SN, Badman T, Rodrigues ASL (2013) Protected areas and effective biodiversity conservation. Science 342:803-805

Lemos MC, Arnott JC, Ardoin NM et al (2018) To co-produce or not to co-produce. Nat Sustain 1:722-724

Liao C, Qiu J, Chen B, Chen D, Fu B, Georgescu M, He C, Jenerette GD, Xia Li, Xiaoyan Li, Xin Li, Qiuying B, Shi P, Wu J (2020) Advancing landscape sustainability science: theoretical foundation and synergies with innovations in methodology, design, and application. Landsc Ecol. https://doi.org/10.1007/s10980-020-00967-0

Mace GM (2014) Whose conservation? Science 345:1558-1560

Martín-López B, Iniesta-Arandia I, García-Llorente M, Palomo I, Casado-Arzuaga I, Del Amo DG, Gómez-Baggethun E, Oteros-Rozas E, Palacios-Agundez I, Willaarts B, González JA, Santos-Martín F, Onaindia M, López-Santiago C, Montes C (2012) Uncovering ecosystem service bundles through social preferences. PLoS ONE. https://doi.org/10. 1371/journal.pone. 0038970

McLain RJ, Banis D, Todd A, Cerveny LK (2017) Multiple methods of public engagement: Disaggregating sociospatial data for environmental planning in western Washington, USA. J Environ Manage 204:61-74 
Miller TR (2013) Constructing sustainability science: Emerging perspectives and research trajectories. Sustain Sci 8:279-293

Moon K, Blackman D (2014) A guide to understanding social science research for natural scientists. Conserv Biol 28:1167-1177

Oksanen J, Blanchet GF, Friendly M, Kindt R, Legendre P, McGlinn D, Minchin PR, O'Hara RB, Simpson GL, Solymos P, Stevens MHH, Szoecs E, Wagner H (2018) Vegan: community ecology package. $\mathrm{R}$ package version 2.5-2. https://CRAN.R-project.org/package=vegan

Opdam P, Luque S, Nassauer J et al (2018) How can landscape ecology contribute to sustainability science? Landsc Ecol 33(1):1-7

Oteros-Rozas E, Martín-López B, González JA, Plieninger T, López CA, Montes C (2014) Socio-cultural valuation of ecosystem services in a transhumance social-ecological network. Reg Environ Change 14(4):1269-1289

Palomo I (2017) Climate change impacts on ecosystem services in high mountain areas: a literature review. Mt Res Dev 37:179-187

Palomo I, Montes C, Martín-López B, González JA, GarcíaLlorente M, Alcorlo P, Mora MRG (2014) Incorporating the social-ecological approach in protected areas in the anthropocene. Bioscience 64:181-191

Peppler-Lisbach C, Beyer L, Menke N, Mentges A (2015) Disentangling the drivers of understorey species richness in eutrophic forest patches. J Veg Sci 26:464-479

Quétier F, Rivoal F, Marty P, de Chazal J, Thuiller W, Lavorel S (2010) Social representations of an alpine grassland landscape and socio-political discourses on rural development. Reg Environ Change 10:119-130

Quintas-Soriano C, García-Llorente M, Norström A, Meacham M, Peterson G, Castro AJ (2019) Integrating supply and demand in ecosystem service bundles characterization across Mediterranean transformed landscapes. Landsc Ecol 34:1619-1633

Raymond C, Brown G (2007) A spatial method for assessing resident and visitor attitudes towards tourism growth and development. J Sustain Tour 15:520-540

Raymond CM, Brown G (2011) Assessing conservation opportunity on private land: socio-economic, behavioral, and spatial dimensions. J Environ Manage 92:2513-2523

Raymond CM, Bryan BA, MacDonald DH, Cast A, Strathearn S, Grandgirard A, Kalivas T (2009) Mapping community values for natural capital and ecosystem services. Ecol Econ 68(5):1301-1315

Raymond CM, Fazey I, Reed MS, Stringer LC, Robinson GM, Evely AC (2010) Integrating local and scientific knowledge for environmental management. J Environ Manage 91:1766-1777
R Core Team (2018) R: a language and environment for statistical computing. R Foundation for Statistical Computing, Vienna, Austria. https://www.Rproject.org/

Reed MS, Evely AC, Cundill G, Fazey I, Glass J, Laing A, Newig J, Parrish B, Prell C, Raymond C, Stringer LC (2010) What is social learning? Ecol Soc 15(4):r1

Reid WV, Berkes F, Wilbanks TJ, Capistrano D (2006) Bridging scales and knowledge systems: concepts and applications in ecosystem assessments. Island Press, Washington DC

Reyes-García V, Aceituno-Mata L, Calvet-Mir L, Garnatje T, Gómez-Baggethun E, Lastra JJ, Ontillera R, Parada M, Rigat M, Vallès J, Vila S, Pardo-de-Santayana M (2014) Resilience of traditional knowledge systems: the case of agricultural knowledge in home gardens of the Iberian Peninsula. Glob Environ Change 24:223-231

Ringle CM, Wende S, Will S (2005) SmartPLS 2.0 (M3) Beta. Hamburg

Ruiz-Mallén I, Barraza L, Bodenhorn B, Reyes-García V (2009) School and local environmental knowledge, what are the links? A case study among indigenous adolescents in Oaxaca, Mexico. Int Res Geogr Environ Educ 18:82-96

Shi J, Visschers VHM, Siegrist M (2015) Public perception of climate change: the importance of knowledge and cultural worldviews. Risk Anal 35:2183-2201

Tallis H, Lubchenco J (2014) Working together: a call for inclusive conservation. Nature 515:27-28

Tengö M, Hill R, Malmer P, Raymond CM, Spierenburg M, Danielsen F, Elmqvist T, Folke C (2017) Weaving knowledge systems in IPBES, CBD and beyond-lessons learned for sustainability. Curr Opin Environ Sustain 26-27:17-25

van Riper CJ, Kyle GT, Sherrouse BC, Bagstad KJ, Sutton SG (2017) Toward an integrated understanding of perceived biodiversity values and environmental conditions in a national park. Ecol Indic 72:27-287

Vías J (2011) Memorias del Guadarrama: historia del descubrimiento de unas Montañas. La Librería, Madrid

Watson JEM, Dudley N, Segan DB, Hockings M (2014) The performance and potential of protected areas. Nature 515:67-73

Xu W, Yi Xiao, Zhang J, Yang W, Zhang L, Hull V, Wang Z, Zheng H, Liu J, Polasky S, Jiang L, Yang Xiao, Shi X, Rao E, Lu F, Wang X, Daily GC, Ouyang Z (2017) Strengthening protected areas for biodiversity and ecosystem services in China. Proc Natl Acad Sci USA 114:1601-1606

Publisher's Note Springer Nature remains neutral with regard to jurisdictional claims in published maps and institutional affiliations. 